\title{
The Student Committee of Sports Medicine Research Center: To be Independent or Not to Be? That Is the Question
}

Asian Journal of Sports Medicine, Volume 2 (Number 2), June 2011, Pages: 124-125

$\mathrm{R}_{\mathrm{i}}^{\mathrm{e}}$ especting the recent promotion of sports medicine in different communities as a new field in medicine, involvement of medical students in sport medicine research similar to other medical research fields seems to be necessary. In this letter, we describe our experience regarding establishment of a student research committee in Sports Medicine Research Center (SMRC) of Tehran University of Medical Sciences. Fortunately, many medical students joined to this committee. These students can guarantee the successful future of this new branch of medicine.

In the light of immense successes of sports medicine specialists in treatment, preventions and rehabilitation of some non-communicable diseases and also increasing number of sports-related injuries, more investigators have been attracted to this new branch of medicine. Quite enough manuscripts have been published to show the importance of sport medicine training for medical students ${ }^{[1]}$. However, to our knowledge, no study has implied on necessity and method of research training for young medical students who are interested in this area.

In 2007, we established the Student Committee of SMRC of Tehran University of Medical Sciences. The aim of this committee was to provide an appropriate academic atmosphere for training and research of those students who want to focus on sports medicine or related fields as their future specialty.

To achieve the goals of the committee, we tried to learn from previous experiences of our friends in other research centers ${ }^{[2]}$. On this base, holding some researchassociated workshops by knowledgeable volunteered members and weekly research methodological and epidemiologic books review meetings were some parts of the research education program applied in this committee. These workshops and meetings could improve the theoretical research knowledge of the members. In addition, running research projects under direct supervision of sports medicine faculty has provided this opportunity for the medical students to involve practically in sports medicine research. Indeed, members of the committee were not allowed to be involved in more than two specific topics of sports medicine researches at the same time. This could help them to concentrate on research projects assigned to them which might lead to better quality of the final work. We believe that if students involve in specific research topics, they will become more expert in that topic in a shorter time.

According to the glowing recommendations of the faculty and those who experienced any kind of collaboration with members of the Student Committee of the SMRC in course of their research, almost all of our members have a quite high level of theoretical and practical knowledge for performing standard research projects. Nevertheless, it seems that for training wellqualified sports medicine scientists in the future, medical students should be encouraged to participate not only in implementation, data acquisition, analysis and manuscript writing, but also in designing, criticizing, and reviewing research studies and articles. Even running research projects by medical students (without supervision of sports medicine faculty) who have been well trained in different aspects of the research is not far from our idea. This can be considered as a double-edged sword; on one hand this might be a jumpstart for the talented members of the Student Committee to have a new experience (research without any supervision by the faculty); on the other hand this might open the gate for wasting research 
budgets of the SMRC without satisfying outputs. However, in our opinion conducting research projects by very well-trained medical students prepare them to meet demands of their future responsibility as leaders of sport medicine research in Iran. Remarkable ability and enthusiasm of the Students Committee's members have been noticed during the past four years. It may be reasonable that the Scientific Board and chairman of the SMRC should pay more attention to this committee and consider allocating a part of the yearly budget of the SMRC as an independent grant for research projects of medical student without involvement of the SMRC faculty as supervisor.
Key Words: Medical Students; Research; Sports Medicine

Mohsen Rostami*1; ${ }^{1}$ Pedram Heidari ${ }^{2}$ MD; Mohammad Abdollahi ${ }^{1}$; Ramin Kordi $^{1}$, MD, MSc, PhD

Authors' Affiliation:

1. Sports Medicine Research Center, Tehran University of Medical Sciences, Tehran, Iran

2. Center for Translational Nuclear Medicine and Molecular Imaging, Department of Radiology, Massachusetts General Hospital, Harvard Medical School, Boston, USA

* Corresponding Author;

Address: Sports Medicine Research Center, No 7, Al-e-Ahmad Highway, Tehran, Iran P.O Box: 14395-578

E-mail: rostami.moh@gmail.com

\section{REFERENCES}

1. Kordi R, Moghadam N, Rostami M. Sports and exercise medicine in undergraduate medical curricula in developing countries: a long path ahead. Med Educ Online. 2011; 16.

2. Shakiba B, Irani S, Salmasian H. A jumpstart for student researchers in Iran. The Lancet 2007;369:1167-8. 